\title{
First Record of the Twin-spotted Wolfsnake, Lycodon jara (Shaw 1802), from Bihar, India
}

Shariq Shafi ${ }^{1}$, Abhishek ${ }^{2}$, Arif Ahmed ${ }^{3}$, Saurabh Verma ${ }^{3}$, Kamlesh K. Maurya ${ }^{1}$, Meraj Anwar ${ }^{1}$, Gaurav Ojha ${ }^{3}$, Ambarish Mall ${ }^{3}$, and Hemkant Roy ${ }^{3}$

${ }^{1}$ WWF-India, 172 B, Lodhi Estate, New Delhi-110003, India (sshafi@wwfindia.net)

${ }^{2}$ TRAFFIC-India, 172 B, Lodhi Estate, New Delhi-110003, India

${ }^{3}$ Valmiki Tiger Reserve, West Champaran, Bettiah, Bihar-845438, India

$\mathrm{W}$

olfsnakes in the genus Lycodon are represented by 50 species distributed throughout southern and southeastern Asia (O'Shea et al. 2018), of which 16 species have been reported from India (Chaudhuri et al. 2015). The Twin-spotted Wolfsnake (Lycodon jara) occurs in India, Nepal, Bhutan, Bangladesh, and Myanmar (Mallik et al. 2014; Chaudhuri et al. 2015), where it inhabits both forested and open landscapes, including agricultural areas (Captain 2010). In India, the species has been reported to occur throughout most of the northern and northeastern states (Talukdar and Dasgupta 1977; Bahuguna and Bhutia 2010; Captain 2010; Das et al. 2012; Khan and Sharma 2018). Dasgupta and Raha (2004) listed 37 species of snakes from Bihar; however, we herein report the first records of the Twin-spotted Wolfsnake from the state.
While on routine patrol, forest staff of the Valmiki Tiger Reserve found snakes (Fig. 1) on 17 August 2019 in the Valmiki Nagar Range and on 6 October 2019 in the Manguraha Range that were subsequently identified as Lycodon jara based on descriptions in Mallik et al. (2014) and Chaudhuri et al. (2015). The closest published locality record for this species is in Hazaribagh, Jharkhand (Khan and Sharma 2018), which is $377 \mathrm{~km}$ from the Manguraha location.

The first sighting took place around $1415 \mathrm{~h}$ on the Bhalu Thapa Forest Road $\left(27.43425^{\circ} \mathrm{N}, 83.94708^{\circ} \mathrm{E}\right.$; elev. $138 \mathrm{~m}$ asl) and the second at $0820 \mathrm{~h}$ near a perennial rivulet $\left(27.32670^{\circ} \mathrm{N}, 84.52206^{\circ} \mathrm{E}\right.$; elev. $136 \mathrm{~m}$ asl). Both localities were in moist deciduous forest dominated by Sal (Shorea robusta) and Indian Laurel (Terminalia elliptica) trees. The

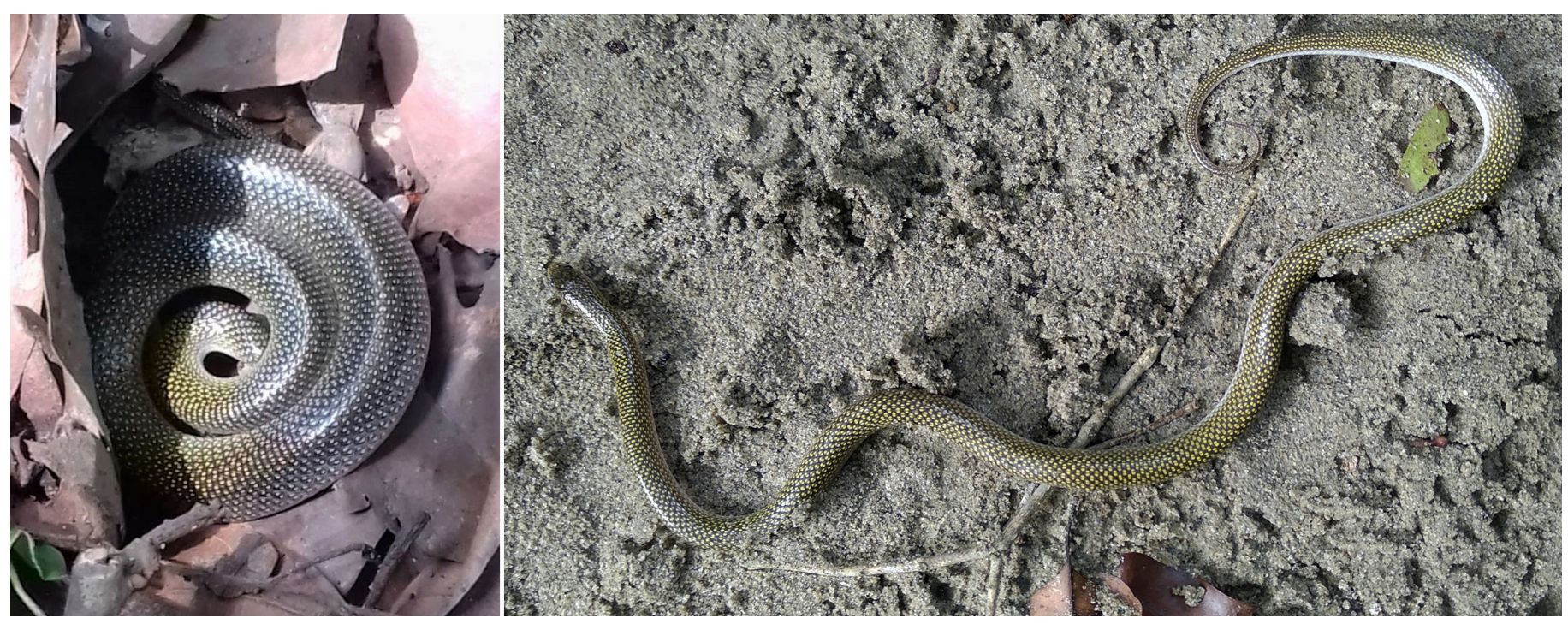

Fig. 1. Twin-spotted Wolfsnakes (Lycodon jara) from the Valmiki Tiger Reserve, Bihar, India: An individual found on 17 August 2019 in the Valmiki Nagar Range (left) and another found on 6 October 2019 in the Manguraha Range (right); note the absence of a light collar in both snakes. Photographs by Mundrika Prasad (left) and Abdur Rehman (right). 
snake from the Valmiki Nagar Range was an adult (total length $-400 \mathrm{~mm}$ ), whereas the individual from the Manguraha Range was a juvenile (total length $-220 \mathrm{~mm}$ ). Neither snake had the light collar that is present in some young individuals (Whitaker and Captain 2004; Mallik et al. 2014; Chaudhuri et al. 2015), although Hussain and Roy (1993) and Shaw et al. (1999) also reported the snakes lacking collars.

\section{Acknowledgements}

We are greatly indebted to the Environment, Forest and Climate Change Department, Government of Bihar, particularly to Principal Chief Conservator of Forests and Chief Wildlife Warden for their constant support. We are sincerely thankful to the forest staff, Mr. Mundrika Prasad, Mr. Abdur Rehman, Mr. Bihari Mahto, Mr. Ramdhar Kumar, and Mr. Vivek Badal, for their hard work and locating the species. We also thank Mr. Subhendu Mallik (General Sectretary of the Snake Helpline and Honorary Wildlife Warden, Department of Forest \& Environment, Government of Odisha) for valuable suggestions and for providing reference materials.

\section{Literature Cited}

Bahuguna, A. and P.T. Bhutia. 2010. Extension of the range and redescription of Lycodon jara (Shaw) (Reptilia: Serpentes: Colubridae). Records of the Zoological Survey of India 110(4): 37-39.

Captain, A. 2010. Lycodon jara. The IUCN Red List of Threatened Species 2010:
e.T176843A7315760. <http://dx.doi.org/10.2305/IUCN.UK.2010-4. RLTS.T176843A7315760.en>.

Chaudhuri, A., V. Sharma, and J. Purkayastha. 2015. Lycodon odishii, a junior synonym of Lycodon jara, with notes on morphological variation in this species (Squamata, Colubridae). Hamadryad 37: 95-103.

Das, A., D. Basu, L. Converse, and S.C. Choudhury. 2012. Herpetofauna of Katerniaghat Wildlife Sanctuary, Uttar Pradesh, India. Journal of Threatened Taxa 4: 2553-2568.

Dasgupta, G. and S. Raha. 2004. Reptilia, pp. 143-179. In: Fauna of Bihar (Including Jharkhand), Part-1. State Fauna Series 11. Zoological Survey of India, Kolkata, India.

Hussain, A. and P. Roy. 1993. Occurrence of Twin Spotted Wolf Snake Lycodon jara (Shaw) (Dipsadidae: Lycodontinae) in Rajaji National Park and Doon Valley, Uttar Pradesh. Journal of the Bombay Natural History Society 90: 112-113.

Khan, A.A. and V. Sharma. 2018. Geographic distribution: Lycodon jara (Twinspotted Wolf Snake). Herpetological Review 49: 506.

Mallik, S., S.P. Parida, A.K. Mohanty, A. Mallik, K.L. Purohit, S. Mohanty, S. Nanda, S. Sindura, S. Purohit, A.T. Mishra, and S. Sahoo. 2014. A new species of wolf snake (Serpentes: Colubridae: Lycodon) from Berhampur, Ganjam, Odisha, India. Russian Journal of Herpetology 21: 205-216.

O'Shea, M., K.I. Kusuma, and H. Kaiser. 2018. First record of the Island Wolfsnake, Lycodon capucinus (H. Boie in F. Boie 1827), from New Guinea, with comments on its widespread distribution and confused taxonomy, and a new record for the Common Sun Skink, Eutropis multifasciata (Kuhl 1820). Reptiles \& Amphibians 25: 70-84.

Shaw, G.E., E.O. Shebbeare, and P.E. Barker. 1999. Snakes of Sikkim and Bengal. Asiatic Publishing House, Delhi, India.

Talukdar, S.K. and G. Dasgupta. 1977. Natural distribution of the wolf snake Lycodon jara (Shaw) (Serpentes: Colubridae) in northern India. Newsletter of the Zoological Survey of India 3: 276-277.

Whitaker, R. and A. Captain. 2004. Snakes of India. The Field Guide. Draco Books, Chennai, India. 